UvA-DARE (Digital Academic Repository)

\title{
The Peculiar Maturation of the History of Science
}

Karstens, B.

Published in:

The making of the humanities. - Vol. 3: The modern humanities

Link to publication

Citation for published version (APA):

Karstens, B. (2014). The Peculiar Maturation of the History of Science. In R. Bod, J. Maat, \& T. Weststeijn (Eds.), The making of the humanities. - Vol. 3: The modern humanities (pp. 183-203). Amsterdam: Amsterdam University Press.

\section{General rights}

It is not permitted to download or to forward/distribute the text or part of it without the consent of the author(s) and/or copyright holder(s), other than for strictly personal, individual use, unless the work is under an open content license (like Creative Commons).

Disclaimer/Complaints regulations

If you believe that digital publication of certain material infringes any of your rights or (privacy) interests, please let the Library know, stating your reasons. In case of a legitimate complaint, the Library will make the material inaccessible and/or remove it from the website. Please Ask the Library: http://uba.uva.nl/en/contact, or a letter to: Library of the University of Amsterdam, Secretariat, Singel 425, 1012 WP Amsterdam, The Netherlands. You will be contacted as soon as possible. 


\title{
The Making of the Humanities
}

\author{
Volume III: \\ The Modern Humanities
}

Edited by
Rens Bod,

Jaap Maat and

Thijs Weststeijn 
This book is made possible by a grant from the Netherlands Organization for Scientific Research.

This book is published in print and online through the online OAPEN library (www.oapen,org).

Front cover: Nikolaus Gysis, München 1892 ... VI. internationale Kunstausstellung, 1892, I892, Chromo-lithographed poster, I2I x $68 \mathrm{~cm}$, printed by Chromotypie v. Meisenbach, Riffarth $\&$ Cie (Munich), Bibliothèque nationale de France, Paris, Département Estampes et photographie (inv.nr. EST ENT DO-I). The original oil painting is in a private collection in Athens.

Cover design: Studio Jan de Boer

Lay-out: $\mathrm{V}_{3}$-Services

Amsterdam University Press English-language titles are distributed in the US and Canada by the University of Chicago Press.
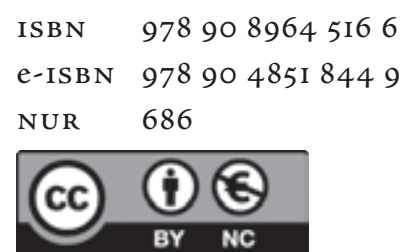

Creative Commons License CC BY NC

(http://creativecommons.org/licenses/by-nc/3.0)

(C) Rens Bod, Jaap Maat, Thijs Weststeijn / Amsterdam University Press B.V., Amsterdam, 2014

Some rights reserved. Without limiting the rights under copyright reserved above, any part of this book may be reproduced, stored in or introduced into a retrieval system, or transmitted, in any form or by any means (electronic, mechanical, photocopying, recording or otherwise).

Every effort has been made to obtain permission to use all copyrighted illustrations reproduced in this book. Nonetheless, whosoever believes to have rights to this material is advised to contact the publisher. 


\title{
3.5 The Peculiar Maturation of the History of Science $^{\mathrm{I}}$
}

\author{
Bart Karstens
}

\section{Introduction}

This paper takes as its topic how the history of science, as a separate field of study, came into being in the early twentieth century and how it developed thereafter. The first signs of the institutionalization of the field as an academic discipline were the first international conference on the history of science held adjacent to the World Exhibition in Paris in 1900, the start of the journal Isis in 1912, and the founding of the History of Science Society in 1924. This journal and the society still occupy a prominent position in the field today. The period also saw the first chairs, textbooks and specialized courses in the history of science come about. To be sure, before the twentieth-century works on the history of science were written. As a matter of fact historians operating in the first half of the twentieth century reacted to the philosophically informed views on the historical development of science of, for example, Comte, Whewell, Mach, and Duhem. ${ }^{2}$ Nothing ever starts in a void. Yet in the nineteenth century nothing resembling a modern academic specialization came about. ${ }^{3}$ For this reason I have chosen the early twentieth century as a starting point of this overview of the development of the field.

Historiography of science is now a respected academic discipline all over the globe. Still, the field has not been institutionalized in a uniform way, for example, as a clearly recognized subdiscipline of the study of history. Historians of science are often not employed by institutes of history but either appear as isolated figures, scattered over the various faculties and institutes of universities, or are bundled in separate HPS (History and Philosophy of Science) or STS (Science, Technology and Society) institutions, quite often with strong ties to philosophy or sociology. The uneasy institutional status of the field is a symptom of profound differences in view on why and how the history of science should be studied. Among historians there is considerable difference of opinion on the purposes and aims of the field, what kinds of knowledge it should produce, by 
what methods this knowledge should be arrived at, etc. One goal of this paper is to demonstrate where these differences come from. The paper starts with a sketch of the aims and goals that the first generation of professional historians of science set themselves. Their work, and the conscious reflection on this work, resulted in the formulation of a number of challenges for the new discipline. During and after the I960s a thorough change in orientation in the field came about. A description of these changes is provided in this paper. We will then be in a position to consider the peculiar aspects of the maturation of the history of science and analyze the most important driving forces behind this process.

The output of scholarly research in the field clearly reflects the major reorientations after the I960s. Yet other orientations, sometimes even opposite to the mainstream, continue to exist. The resulting picture of the current status of the field therefore is one of disorder. The variety in approaches to the history of science can, to some extent, be viewed as a healthy form of pluralism. Yet there is also an aspect of unhealthy 'anarchy' because fruitful exchanges of thought about the relative worth of the approaches, the possible compatibility of assumptions, etc., are rather scarce. ${ }^{4}$ This signals the need for reform. In the final section of the paper I argue that a road toward more unity in historiography of science can be found if two things are taken seriously. First, the recognition that the strong ties of the field to the natural sciences and to philosophy were not accidental. Aiming to gain complete independence from these 'parent' disciplines must therefore be considered as a wrong-headed project. Second, the recognition that the challenges to the profession that were already formulated by the first generation of professional historians of science are still relevant today. It is with respect to these challenges that a new balance must be struck. These considerations show how the study of the history of a discipline can be relevant to the operations of that very discipline in the present.

\section{Aims of the field in the first phase of professionalization}

The central figure in the first phase of the institutionalization of history of science was George Sarton (1884-1956). Sarton was of Belgian origin but gained recognition as a professor at Harvard University. Sarton taught history of science there for many decades. Among his students were important later scholars in science studies, such as I.B. Cohen and Robert K. Merton. He was also instrumental in Alexandre Koyrës move to the US, where he became highly influential. Sarton set up the journal Isis and was its editor-in-chief for many years. He was also involved in the creation of the History of Science Society. Sarton's role in the institutionalization of the discipline is widely recognized. Of interest here are the 
programmatic essays he wrote about the relevance of the field, not just to the rest of the academic system but to society as a whole, and the way it should be studied and taught to students. The arguments and motivations he gave for a thorough study of the history of science by way of a specialized academic discipline form an interrelated whole that is worthwhile to unravel. Sarton's views will also be compared to the views of his contemporaries; this comparison yields a good picture of the prevailing ideas with respect to the study of past science during the first phase of its professionalization.

Sarton saw science as the only human activity in which progress had been achieved. According to him the progressive force of science also had profound effects on society, especially in modern times. It was through science that the improvement of living conditions became possible and science also showed the way to improve the organization of society. Furthermore Sarton saw the striving for pure knowledge as a moral quest. Good scientific research was a disinterested search for the truth and this attitude brought about the most outstanding achievements the human mind was capable of.

For all these reasons Sarton argued that the scientific enterprise had to be dealt with great care. If science fell into the wrong hands, or if it were practiced in the wrong way, this could only be harmful to society. A mistaken approach to science was not just a symptom of a bad regime: it could well be conducive to wrong political systems. ${ }^{5}$ Another danger was that scientists could start to overrate themselves and the importance of their contributions. Such hubris needed a check at all times. In premodern days people were kept in check by a clear social hierarchy: the church or the nobility. In modern times such social hierarchies, and the institutions connected to them, have only a marginal hold on people. Thus other forms of (institutional) control were needed.

Now Sarton firmly believed that modern historical consciousness could replace the older forms of social control if it was embedded in a spirit of 'new humanism. The old humanism had known three categories: the natural, the human and the superhuman. The superhuman was thought to be the highest category, the natural to be the lowest. It followed that the study of man was also more important than the study of nature. This needed to be changed, according to Sarton. In his 'new humanism' the superhuman category disappeared and the study of man gained equal status with the study of nature. Only the combination of study of both fields could save humanity from the so-called technocrats: scientists who had become specialists in their own fields, who had no respect for the humanities and a total lack of appreciation of the unity of science. According to Sarton the role for the history of science in bringing this new humanism about was crucial: 'Between the old humanist and the scientist, there is but one bridge, the history of science, and the construction of that bridge is the main cultural need of our time. ${ }^{6}$ 
Why was the history of science needed for this? Why not just concentrate on the products of modern science? Sarton answered this question by pointing to the complementary tasks of science and the historiography of science. For him there was no difference in principle between these fields. Both science and the study of its history worked toward the same goals, namely the acquisition of knowledge. It is only that the tasks of historians and scientists were different. Whereas the scientist investigates nature and comes up with experimental and theoretical results, the historian should act as a critic of the products of the scientist, like art critics value the work of artists. Sarton thought that: 'There can be no real understanding of science, that is, there can be no science, without continuous criticism of it." This continuous criticism is the most important check on the dangers involved in the growth of knowledge and technology. On top of debates held within the scientific community, the historian was in a position to deliver such permanent criticism because he or she possessed the scholarship to place the products of the scientist and the debates held in scientific communities in a larger perspective and evaluate the new contribution with respect to the foregoing tradition. In this way historical understanding and current scientific research met and only a professional historiography of science could provide the needed bridge.

Apart from being a critic, the historian should also act as a guardian. One of the main tasks of historiography of science was to establish the good tradition and do away with things that do not belong to it such as superstitions, undeserved privileges, (willful) error, etc. This good tradition was not a story of immutability. Tradition for Sarton was a dynamic force, not an endless repetition of the same behavior. He saw the good tradition as a sequence of the right steps. Only when this good tradition was safely protected could new discoveries and new claims to knowledge be assessed properly. The historian must thus be evaluative with respect to the past and present but not in the simplistic sense that everything in the past that contradicts present-day knowledge should be considered as bad science. Science progresses toward the truth but this road is difficult and almost every scientific theory so far has proven to be open for revision. The methods by which this constant revision is possible are thus of central importance to the whole endeavor.

It was equally important that the historian highlighted the human dimension in this process. Historians had to concentrate on the nonlinear development of science. Gathering knowledge about the world was a difficult process, which required a lot of effort. In the long run, with the benefit of hindsight, it is possible to see patterns and logical sequences but when focused on shorter time spans great struggles can be seen, hard work, wandering down wrong paths, periods of puzzlement and conflicts with others, victories and losses, etc. Clearly it was one of the historian's tasks to highlight these struggles in narratives about the past. 
'New humanism' thus also meant that the human effort that had to be put in to unravel nature's mysteries gained the highest respect: 'The New Humanist is of all men the one who is most conscious of his traditions and of the traditions of mankind. He admires the wonders of science but the greatest wonder of all he reflects is that man revealed them.'

Finally, historians of science should become, perhaps somewhat paradoxically, specialists in generalization, and obtain long-term views lending unity to all scientific efforts. The general picture should act as an antidote to today's delusions and create the right attitude to science by sorting effects of moderation, patience and, most importantly, humility. Scientists are after the truth and their theories are converging toward it but they need to bear in mind that their ideas are continuously subject to revision. Knowledge of the history of science can help to critically evaluate present scientific ideas. Thus acquaintance with the history of science could have the following benefits: be an inspiration for current scientists, act as a check on claims of originality, lend a scientific attitude to further scientists' investigations and provide useful morals for present-day research.

In education the historian had to teach what science was about, its function and methods, its psychological and sociological implications, its deep humanity and its importance for the purification of thought and the integration of culture. In order to do all this a historian of science had to be an expert in history, have a good command of the state of the art in the sciences of both his or her own day and the past, be able to interpret past sources well (Sarton was also an empiricist), and also be a good writer and an able teacher.

Taken together, and especially in an age of rapid discipline formation, the task was obviously impossible for a single scholar to perform. This is precisely the reason why Sarton put so much effort in the institutionalization of the field. The unearthing of the sources and the interpretations of all episodes of the history of science for the most part still needed to commence. A great number of people was needed to perform such an abundance of detailed research projects. Good communication channels and an institutional platform for bringing all this knowledge together, passing it over to future generations and eventually build syntheses out of them, was therefore absolutely necessary. Otherwise historiography of science could never perform the important tasks Sarton had placed on it. And since these tasks were for him of crucial importance to the well-being of mankind as a whole, he devoted much energy to the legitimatization of the study of history of science as a separate discipline and the institutionalization of the field in the academic world.

According to Kragh, Sarton's program was never carried out in practice. ${ }^{9}$ There is, however, serious reason to doubt this. First the well-known historian of science A. Rupert Hall noticed a great influence of Sarton's ideas in Cam- 
bridge at the onset of professional historiography of science there. He writes: 'the broad notion of the literate scientific culture, at once rigorous and humane, agnostic and experimental, which Sarton called the New Humanism had become widespread during the first half of the century' ${ }^{\prime \circ}$ Apart from such direct references the similarities between Sarton's programmatic writings and the work of other historians such as Alexandre Koyré (I892-1964), E.A. Burtt (I892-1989) and E.J. Dijksterhuis (1892-I965) are striking. These historians did not write lengthy programmatic essays but were all occupied with establishing the good tradition, with the issue of humanism and with the philosophical dimension of science.

In the writings of both Koyré and Burtt we find the view of science as the most successful movement of thought history so far records. But in both we also find comments on the downside of the progress that modern science brought, not unlike Max Weber's ideas on the disenchantment of the world. According to Burtt the dominance of modern science in Western culture had led to a downgrading of the human spirit. It was the central task of philosophy 'to reinstate man with his high spiritual claims' ${ }^{\text {II }}$ rather than let him become a mere entity reducible to the atomic categories of modern science. The remedy for this, according to Burtt, was to reconnect science in each historical period to the philosophical or metaphysical ideas that reigned supreme in these periods. The quest for scientific knowledge could be properly understood only in connection to these philosophical schemes. Hence the title of Burtt's work, The Metaphysical Foundations of Modern Physical Science (1924). The fear of dehumanization is expressed in different terms than in the work of Sarton, who considered the scientific process dangerous, not in itself, but only if the control of science fell into the wrong hands. Yet the remedy both come up with is strikingly similar: a firm connection between the sciences and the humanities is needed in order to benefit most from the advancement in scientific knowledge.

Koyrés ideas, although slightly different again, can easily be compared to the views of Burtt and Sarton. Like Burtt, Koyré too argued for the importance of studying philosophical schemes of the past. For him general mental frameworks could not be separated from scientific research: in every period scientific thought must be related to the 'thinking cap' prevalent in the period. In effect this can be seen as the start of contextualism in historiography of science. ${ }^{12}$ What made the seventeenth-century breakthrough in science possible for Koyré was a change from Aristotelianism to Neoplatonism. The latter brought with it the idea that reality was to be captured in mathematical terms. From a world of 'more or less' people started to live in a universe of precision. It was chiefly Galileo who brought this revolution about. For Koyré, Galileo's approach to science was basically the right one. ${ }^{13}$ 
The praise for Neoplatonism was shared by Dijksterhuis, who launched the idea of a mechanization of the world picture, which was in fact a mathematization of the world picture. ${ }^{14}$ A considerable difference of opinion with Koyré was that Dijksterhuis did not consider reality as fundamentally mathematical. He saw mathematics as a way of describing that gets us as close to reality as we can. Yet they both had a decidedly anti-positivist attitude, as can also be read off from Koyré's slogan that 'good physics is done a priori'. Thus there was a great difference with Sarton, who very much wanted to align history of science to the positivist project in philosophy. Yet what is most important for the present purposes is to see that they all tried, in very different ways to be sure, to relate the study of past science in one way or another to philosophy, thereby finding a way to distinguish the good tradition in science from the bad.

Cohen has summed up Koyrés achievements in the following way:

Let there be no mistake about it: Koyré had a most powerful message. It had all the strengths of a unitary account in which, through the magnetic action of the core conception, a huge number of hitherto unrelated historical facts were now arranged, like so many iron filings, along neat lines of force. $^{15}$

That core conception was the Scientific Revolution. In Sartonian spirit Koyrés unitary account combined the search for the right place of the human aspect in the development of science, the aim to distinguish the good tradition from the bad, and an attempt to secure a fundamental place for philosophy in writing of the history of science. The similarities in outlook on the goals and aims of the new profession are striking. The execution of them led to a number of challenges that, as will be argued, have remained pressing, especially for the study of past science in our day.

\section{Challenges to the profession}

Gradually historians started to doubt the value of sketching 'big pictures' of the history of science because these appeared to be centered too much on the present instead of the past. Therefore stories of the good tradition, spanning long periods of time, possibly held together with unifying concepts, are nowadays invariably set aside as 'Whiggism'. In general one speaks of Whig history when the historical process is accounted for with present outcomes in mind. This lends the historical process a form of necessity and for this reason presentist schemes for the organization of historical narratives are mostly rejected. Next to presentism three other 
Whiggish 'sins' can be associated with history of science, namely judgmentalism, triumphalism and internalism.

All these four aspects of Whiggism apply to the historiography of science that was produced until roughly the I 960 s. It was presentist in the sense that historians sought to establish the string of ideas that had led to the present-day state of scientific knowledge. It was also presentist in its objectives: to keep contemporary developments of science in check by historical awareness. It was judgmental in the sense that studying the history of science led to inferences about what the correct way of doing science was. It was triumphalist as science was seen as potentially beneficial to mankind and achievements in science, especially during and after the Scientific Revolution, were seen as the highest achievements of mankind. It was internalist in the sense that an influence of the so-called 'external' factors, such as social, economic, political and cultural factors, on the course of science was hardly recognized. Although a start of contextualism can be witnessed, this contextualism applies only to the wider mental, spiritual or philosophical context, and certainly not to the socio-cultural context.

It comes as no surprise, then, that historians who did begin to put emphasis on an analysis of the socio-cultural context in order to understand past science set aside the work of their predecessors as Whiggish. A recent example is Steven Shapin, who sees in Sarton no more than a triumphalist. He explains this triumphalism by Sarton's institutional aims. The high achievements of the past were a good selling point for the study of history. When historiography of science had become a recognized discipline in the university system, Shapin argues, there was no longer any need for exaggeration and a process of 'lowering the tone' could begin ${ }^{16}$ There is maybe some truth in this analysis but in general I believe it can be harmful to brush off the older historiography of science as Whiggish with the implication that the work, as well as the incentives behind this work, can be considered irrelevant. In this way one loses sight of important motivations to engage in historical study of the past and equally important deliberations on the discipline's aims and the prospects of and problems in achieving these aims.

The first generation of professional historians of science certainly was not naively Whiggish. There was keen appreciation of the struggles of past scientists and their modes of thinking. Not everything that must be considered wrong from the standards of present-day science was simply rejected as uninteresting or as bad science. Being an important link in the chain toward the present was the most important criterion to assess the science of the past. Progress was also not seen as a linear, gradual and smooth process, as an extreme Whig account of past science would have it. However, dividing the concept of Whig history into four aspects, presentism, judgmentalism, progressivism/triumphalism and 
internalism, allows for a more balanced approach to 'Whiggism'. It is quite well possible that interpretations of these aspects can be formulated without turning them into a 'Whiggish sin'. It is, for example, not difficult to see that any form of historiography contains a degree of presentism, for the simple reason that the historian can never fully shake off his or her own rootedness in place and time. Moreover with the rejection of Whig history talk of progress has been abandoned in historiography of science. One can, with Elzinga, wonder whether this effect of the use of the notion of Whig history is desirable: "The reproach has become a shibboleth, which is placed in position against anyone who claims that science is in progress at all, ${ }^{17}$

It is indeed important to recognize that the term 'Whig history' with reference to the historiography of science only came in use from the 1970 s onwards. ${ }^{18}$ If one searches the word in the Isis database one sees references to the term increase dramatically only from the 1980 s onwards. This suggests that the usage of the term has played a role in the legitimatization of new approaches to past science (see the next section). Dismissing former approaches as naively Whiggish then appears also to have been a rhetorical strategy. This strategy leaves all kinds of questions unaddressed. If triumphalism was needed to legitimize the field, the question why the historiography of science was needed as a separate academic field is still open. Why were the concerns with humanism so strongly present in many scholars? And if the present was thought so important, why was a study of the history of science needed? Why not just devote all effort to present-day science? Only by zooming in on the 'unitary' accounts of scholars like Sarton and Koyré can we find answers to such questions. The uptake of this paper is that a number of challenges to the profession that can be extracted from this, have lost none of their relevance today. These challenges have in common that they are all about striking a right balance between generalism and specialism.

The first of three challenges is the tension between the universalist aspirations of historiography of science and the increase in specialization in the natural sciences. How to satisfy the aim of maintaining a general overview of the whole development of science if it becomes so enormously complex? Even groups of historians cannot keep up with the specialism required to understand what is going on in all the separate disciplines and subdisciplines. ${ }^{19}$ The issue of unity between past and present is at stake here as well as the issue of unity between science and history of science which Sarton, in particular, envisaged as complementary endeavors. A gap in expertise was already felt pressing before World War II. The continuing relevance of the problem can, however, be seen in the so-called 'Science Wars' in the I99os. In this period historians or sociologists of science were blamed by natural scientists for not having a clue about what they were talking 
about in terms of the content of scientific theories. On the other hand natural scientists were blamed for ignoring the impact of contextual factors on the course of science. Both camps argued that the other camp was, through fundamental ignorance, not in a position to offer serious critique, analysis or interpretation of past and present science. The way these 'Science Wars' were conducted strikes one as not very fruitful and the debate in the end was quite inconclusive. ${ }^{20}$ Sarton's worst fear of a separation between the sciences and the humanities appeared to have come about!

The second challenge involves the tension between the generalist attitude of the historian and the need to stay close to the sources. For Sarton generalization (the creation of larger historical syntheses) over detailed case studies was justified only after work on the primary sources had been done. Since in later generations the number of relevant factors to consider expanded dramatically (see the next section) the number of sources to take into account expanded as well. A decidedly empirical attitude then blocks the way to setting up a grand historical narrative about science. Sarton could still maintain a relatively simple conception of the good tradition and how to account for it, but such a thing is no longer possible today. The question the field has yet to answer satisfactorily is what the proper level of generalization is and how to connect this to detailed studies of source material tied to historical localities.

A final point of tension is the relation between philosophy of science and historiography of science. Next to the natural sciences, philosophy of science must be considered as the mother discipline of the historiography of science. Clearly during the first period of professionalization the ties to philosophy were quite strong. In Sarton there was an emphasis on positivism; others sought to connect past science to its metaphysical backgrounds and held the turn to Neoplatonism in high esteem. Moreover all historians were involved in the philosophical project of setting up criteria for what good science consists of and this model of good science was surely meant to be context independent. Philosophical thinking led to overarching normative models of science. Historical research was done in order to demonstrate or test such philosophical models. Today most historians abhor such historiography and the implication is that philosophy is mostly kept at a distance. Yet weakening the ties to the natural sciences and to philosophy of science did not lead to independent historical scholarship as ties to the social sciences such as sociology and anthropology were set in place. In the next two sections this profound change in orientation will be addressed and analyzed. We will then be in a position to assess the significance of the three challenges to the profession as it is currently practiced. 


\section{Changes to the profession}

After World War II attention for the study of the history of science grew considerably. In the US chairs were created at the insistence of not only university policy makers but also general politicians. ${ }^{21}$ Yet according to Kuhn professionalization in historical scholarship proceeded slowly. In a tribute paper to commemorate Sarton, Kuhn offered some valuable insights into the status of the field of the historiography of science in the 1950s. In hindsight he felt the field offered an amateurish sight. There were regular meetings of the History of Science Society but these were relatively small conferences, sometimes even held at the home of one of the members of the society. Moreover, Kuhn himself was appointed lecturer in the history of science while having had no training in that field whatsoever. He observed that such a thing would be impossible in the I980s. Kuhn did not express any nostalgic feelings about this period and claimed that, in spite of all the efforts before, the professionalization of the discipline started only when his generation set out to work..$^{22}$

This much-needed increase in historical sophistication occurred against the background of changing perspectives on the benefits of science for mankind. Science was also seen as standing at the root of many negative things such as dehumanization and alienation, pollution and dramatic forms of warfare. Perhaps the gain in scientific knowledge did not automatically lead to improvements in human life. Perhaps scientific progress was a myth. To address the fear of loss of control it was necessary to lower the tone of science. ${ }^{23}$ Because it put science on a high pedestal, making it something sacred and inaccessible, the universalist ideology was seen to be part of the problem and not part of the solution as the older generation had thought. The concern with improving society, that was clearly present from the beginning of the process of professionalization, remained, but became articulated in a completely different way as new approaches to (past) science came into being.

These new approaches invariably started to stress the contingent aspects of the historical process. The main idea became to understand past science on its own terms. Kuhn's notion of the paradigm demonstrates the shift in attention well. ${ }^{24}$ In its most common interpretation a scientific paradigm is a 'closed' system consisting of theories, methods of research and standards of evaluation, but also of a set of values, principles and background assumptions. This set is informed by the social and cultural factors dominant in a given period and/or place. All aspects together determine what normal science is within the paradigm. When a shift occurs to a new paradigm Kuhn argued that no cumulative process of increase of knowledge should be assumed, as the perspective on things, even on the most fundamental concepts like time and space, could 
change dramatically. Thus the next paradigm should be understood on its own terms again, and so on. ${ }^{25}$

Older science students were aware that reality was not easily mirrored in scientific theories but they did not imagine that the relationship could be so complex with a multitude of contextual factors operating on it. ${ }^{26}$ Yet even Kuhn's model of science as moving from paradigm to paradigm can nowadays appear as a bit old-fashioned. A paradigm for Kuhn could last very long, for example, the Newtonian paradigm that held sway from roughly I700 to I900. Moreover within a period of normal science the focus on scientific ideas is still quite dominant. Sociologists and historians after Kuhn found all this too schematic and too abstract. ${ }^{27}$ They argued that research should focus on concrete local circumstances and the concrete interaction of people and things. Ideas were not just floating in the air but their emergence and acceptance or rejection should be understood in terms of these interactions. The maturation process of the history of science has therefore been one of increasing localization.

This process can be captured in two ways. It can be viewed as a process of increasing naturalization of the study of past science. By 'naturalization' I mean here the approach to explain science in causal terms. This can be done on the following levels: social interaction, man-nature interaction, psychological processing and historical factors. ${ }^{28}$ It depends on the specific approach to past science which form of causal interaction is given the most dominant explanatory force. The naturalist approach is opposed to the formal approach to the study of science, which aims to establish a logical succession in the historical process of theory replacement and seeks to identify relations in the total body of scientific knowledge by the use of formal logic. The formal approach has close ties to philosophy and has been increasingly rejected in favor of naturalist projects in history of science. Fields apt to serve such projects are the social sciences and also the study of history, broadly speaking.

Another way to capture the change in orientation in the study of past science is in terms of symmetry. The principle of symmetry, introduced to the study of science by sociologist David Bloor in 1976, orders us to study both true and false claims to knowledge in the same manner, i.e., symmetrically. For Bloor it is not the case that 'good' science can be explained by reference to a set of rational or formal rules and deviations from good science by reference to 'disturbing' social factors. Instead all acceptance and rejection of theories should according to him be explained by reference to the same type of factors, namely social factors. There may be other factors in play but social factors (meant in the widest sense possible) ultimately determine the course of science, for example, in the settling of scientific controversies. ${ }^{29}$ Norms of rationality cannot be used to explain past science but acceptance of norms becomes itself a topic of investigation. The rationale of 
this approach is to gain a better grasp of the decision-making processes in science. A deeper understanding of these social processes would yield more control over the scientific enterprise and possibly minimize harmful effects to society. Note that the distinction between 'internal' and 'external' is given up. In any historical context acceptance and rejection of knowledge claims is inextricably mixed up with all the societal factors present in that context. ${ }^{30}$

It has proven possible to erase more boundaries and expand the reach of the symmetry principle. ${ }^{31}$ Such generalized principles of symmetry declare even more things as topics of investigation, instead of using them as explanatory resources. In other words, analytical concepts and models are increasingly replaced in favor of a purely descriptive approach of rigidly following the actors, perhaps not far remote from the old Rankean spirit of 'bloss zeigen wie es eigentlich gewesen'. ${ }^{32}$

What these programmatic changes have meant for the research agenda of historians of science has been brought together by Golinski in a useful survey. ${ }^{33}$ The following themes dominate this agenda: study of scientific and experimental practices (practical turn), focus on material circumstances, instruments and objects (material turn), focus on linguistic practice, discourse analysis, communication, representation (linguistic turn), attention to the places of research (geographical turn), the institutionalization process of universities, scientific disciplines, etc., the interaction of science and the public and the self-fashioning of scientists. To this list a number of socially oriented topics such as relations of trust and authority among scientists, relations between science and politics and the interwovenness of economic and scientific developments can be added (social turn). Golinski argues that this list of topics has become what mainstream historiography of science is occupied with. I agree with this and add that this continues to be so to this day. As a Belgian historian recently put it: 'It is widely accepted among historians of science that the production of knowledge is first and foremost a localized process $[\ldots]$, the localized setting plays a crucial role in understanding its conceptual and epistemic features. ${ }^{34}$

\section{A peculiar process of maturation}

It is strange that the development in approaches to historiography of science has ended in a form of Rankean historicism, the model general professional historiography started out with at the beginning of the nineteenth century, but that has long become obsolete. ${ }^{35}$ How can we account for this? Behind the process of naturalization of the study of past science two driving forces can be discerned. Lorraine Daston once said that 'all epistemology is born in fear'. These two driving forces can both be seen as being born in fear. The first force I call the striving 
for liberation. By liberation I mean the freeing of dogmas, norms and standards, Eurocentrism, Westernization, elitism, etc. There is a moral component in this. In presenting the development of science, both in terms of its knowledge claims and in terms of its institutions, as a highly contingent process and in denying that there exist transcendental norms with which all scientific activities and products can be judged, space is created to treat all actions and motives of past historical actors with equal respect. Further, stepping back from the modernist progressive project creates room for a critical engagement with this project, which staunch adherents of modernism are not willing to undertake. All this relates to a fear of objectivism: the dehumanizing force of science that destroys essential aspects of man's life - something that bothered Burtt and Koyré. Perhaps it is ultimately a Romantic fear, as one of the points of Romanticism was to free the individual from the mechanistic and deterministic schemes that Enlightenment thinking had produced.

The second driving force I have called the striving for exactness. An empiricist attitude of being as exact as possible in explications of past science shows itself in the approach to investigate concrete causal relations. Pointing toward 'influences' of persons, ideas or movements on scientists is not enough but must be made concrete by identifying patterns of interaction. This approach has gradually gained the upper hand in the historiography of science. Grand narratives or large-scale comparisons are eschewed because they are regarded as speculative. This is the scientific side of the abolishment of a priori analytical concepts, or philosophically informed interpretive models of past science. Historians do not want to be reproached for being unscientific and therefore they insist on the most exact proof they can get. This fear of being unscientific relates to a more general fear of subjectivism. Once progressive ideals and transcendental standards are given up there is nothing to go by and hence the door is open for subjective speculation. Only an insistence on proof of concrete causal interactions can keep this door closed.

The two fears are clearly different as one leads to a striving for less determination whereas the other leads to a striving for more determination. Yet strangely both lead to the same direction in historiography of science. Both lead to a localist and descriptivist type of historiography. ${ }^{36}$ This becomes understandable if the striving for liberation is interpreted as an avoidance of prescriptivism. To let the past speak without fitting it into all kinds of straitjackets is not incompatible with an empiricist attitude of deriving theories from facts and being wary of too much theoretical speculation.

A conscious estrangement of philosophy and the natural sciences has occurred in connection. Historians of science no longer wanted to work in service of these disciplines and claimed independence instead. This, however, has proven more easily said than done. Interpretative models from the social sciences have started 
to exert a strong influence on the field and cannot easily be passed by. And if the return to a naive historicism is the price that needs to be paid to become a fully recognized historical subdiscipline then this price is surely too high. ${ }^{37} \mathrm{I}$ am drawn to the conclusion that to gain complete independence for historiography of science is a mistaken goal. It belongs to the peculiarities of historiography of science that it really is a discipline that stands on a bridge between the natural sciences and the humanities. The subject matter historians of science have to deal with, the products of the sciences, together with the humanistic methods of studying and interpreting the past dictate this. Trying to gain independence by cutting off the bridge from the banks would be self-destructive. In light of this conclusion, and in light of the analysis of the developments in the approach to past science in mainstream historiography of science, the three challenges to the profession formulated above require renewed attention.

\section{Back to the challenges}

In the development of approaches to the history of science the common aim has been to loosen the ties to the natural sciences and to philosophy. This enterprise has been driven by lofty ethical and scientific ideals but the end result of the process is nonetheless unsatisfactory. We were drawn to the conclusion that the relation between historiography of science and its 'parent' disciplines has to be taken seriously. The challenge then is not to gain independence by cutting ties with these disciplines but to reconceptualize the relations between historiography of science, philosophy and the natural sciences. This challenge fits in remarkably well with the three challenges formulated above of striking the right balance between generalism and specialism. On all scores, the history of science has started to lean over to specialism. The danger of this is that the field is losing its relevance.

The first challenge was to address the tension between maintaining a universal picture of scientific development and the dramatic increase in specialization in the sciences. To place all the developments into the larger picture is very hard to do since it runs against the problem that highly specialized knowledge is needed for that. This is not something historians of science can easily acquire. The solution that has been followed by historians of science is to break off the past from the present and focus on past science, forbidding the use of present-day scientific knowledge in historical explication. This approach can, however, backfire, even when the aim is just gaining a better understanding of specific historical episodes. Although this has to be handled with great care, it can be argued that modern ideas about phenomena with which past scientists also struggled can help in explicating past science. ${ }^{38}$ In order to make proper use of modern scientific knowl- 
edge in accounts of past science cooperation needs to be sought with present-day scientists. Scientists can benefit from this cooperation too as historical scholarship can be of aid in present-day research. ${ }^{39}$

The second challenge was to come up with a proper level of generalization. The prevalent empiricism in the historiography of science nowadays blocks generalization very quickly. The problem with a full empiricism, in which almost anything is declared a topic that requires explanation, is, however, that selective criteria of what is relevant in the past fail us. To describe everything is not only impossible - the past is far too complex for that - but also undesirable. It would be just a reproduction of the past without any gains or insight. One can wonder what purpose the description of all the interactions between actors in the past serves since there is no longer a clear research agenda behind it. ${ }^{40}$ Although historical scholarship has markedly improved over the years, in the end the two forces driving the process have overshot their goals. They put restrictions on the tools of analysis historians of science are allowed to use and these restrictions lead to unwelcome consequences. The challenge is to retreat a few steps without relinquishing the abundance of insight that the symmetrical approaches to past science have brought. How to achieve this is one of the harder questions as it is very easy to slide back into Whig history or to the re-instantiation of normative philosophical models of science that do not square very well with the actual course of history.

Yet philosophy is indispensable for finding the way forward. Thomas Kuhn observed that particularly in periods of acknowledged crisis, scientists have turned to philosophical analysis as a device for unlocking the riddles of their field'. ${ }^{4}$ This holds for historians of science as well, who still have to unlock the riddle of the connection between the general and the specific. This brings us to the third challenge: How can we envisage the relation between the historical (specific, concrete) and the philosophical (general, abstract) study of science?

It is good to recognize that in spite of all the rhetoric philosophy has never been cut out completely in the science studies. As a matter of fact, the shift in orientation toward past science was supported by philosophical arguments and new approaches were founded upon philosophical ideas. For example, the ideas of the later Wittgenstein on rule following, language games, life forms and 'meaning is use' or Quine's naturalist epistemology and his holistic approach to scientific knowledge have played a profound role. ${ }^{42}$ Philosophy has thus been out only on the surface. Philosophical debates about science have continued and 'symmetrists' have amply taken part in them. ${ }^{43}$

All this is an indication that the role of philosophy in any approach to the study of science is indispensable. To satisfy the need for a new analytical framework one has to turn to philosophy. Historians no longer have to be afraid that 
philosophers do not recognize the value of their work. Historical winds have blown hard enough through the ranks of philosophy for philosophers to recognize an important role for history in their models of science. Clear examples are projects in normative naturalism (Laudan, Rouse, Mayo), specific formulations of the analogy between science and evolutionary theory and new developments in thinking about the concept of error. ${ }^{44}$ Such projects, however, have not found their way into the community of historians of science yet. Perhaps reaching out to them still requires shrugging off stereotyped images of philosophy and Whiggism in the community of historians of science.

Another option would be to seriously investigate the merits of comparative historiography for the history of science. The suggestion is very logical because comparisons bring about a connection between what is specific and what is general. When two particular historical localities are compared, what is present in both automatically becomes more general whereas what is present in only one context remains specific. Both findings can be valuable for historical explanation. Yet setting up a comparative framework for the historiography of science is not an easy task since the general intuition needs to be articulated in more specific terms with respect to the level of comparison, the suitable units of comparison, the steering role of prior analysis and the manner in which the results of comparative investigations need to be evaluated. Also comparativism has received a bad press among historians of science because of the projects of Needham and Zilsel that started out before World War II, which are mostly seen as just another version of Eurocentrism. So serious scruples need to be overcome. ${ }^{45}$

Whatever the next turn in the historiography of science will be, a general perspective is involved in any approach to past science. Different approaches to the history of science can lead to different views of what science actually is. The whole enterprise then is profoundly philosophical, just as every really good historiography is. A conscious use of this insight may help to restore some of the old aims of the field: to be general, to be critical, to act as a bridge between the sciences and the humanities, to channel progress into the right direction and to contribute to the improvement of society.

\section{Notes}

I This work is part of the research program 'Philosophical Foundations of the Historiography of Science' financed by the Netherlands Organization for Scientific Research (NWO). I thank my colleagues in the program at Leiden University for their valuable comments and suggestions.

2 See Helge Kragh, An Introduction to the Historiography of Science (Cambridge, I987); George Sarton, A Guide to the History of Science: A First Guide for the Study of the History of 
Science with Introductory Essays on Science and Tradition (Waltham, I952). Contributions to historiography of science by Whewell, Duhem, and Mach are discussed in $\mathrm{H}$. Floris Cohen, The Scientific Revolution: A Historiographical Inquiry (Chicago, 1994), 24-53.

For example, none of the best-known historians of the period such as George Sarton, Alexandre Koyré, Lynn Thorndike, Edwin Burtt, Eduard Dijksterhuis, or even Thomas Kuhn was educated as a specialist in history of science, or even in history in the case of most of these.

4 I am in agreement here with Nicholas Jardine who perceives 'theoretical anarchy' in the field in N. Jardine, 'Sammlung, Wissenschaft, Kulturgeschichte', in A. te Heesen and E.C. Spary (eds.), Sammeln als Wissen. Das Sammeln und seine wissenschaftsgeschichtliche Bedeutung (Göttingen, 200I), I99-22 I.

5 Sarton opposed both communist and fascist systems. After the war he saw his opinions confirmed when the horrifying scientific experiments of the Nazis became known. He also went as far as to say that Hegel was not well versed in science, because he had declared in his dissertation that the number of planets could not exceed seven on principle, and thus it was not a coincidence that his dialectic philosophy led via Marx to communist ideologies: G. Sarton, A Guide to the History of Science, 2nd lecture.

6 George Sarton, The History of Science and the New Humanism (New York, I93I), 72. The plea for 'new humanism' is much less quoted but essentially very similar to C.P. Snow, The Two Cultures and the Scientific Revolution (Cambridge, I959). Even the political concern with totalitarian systems is similar: Sarton wrote against fascism and Snow warned against communism. The similarity is also noted by $\mathrm{H}$. Floris Cohen, 'De wetenschapsrevolutie van de $\mathrm{I} 7^{\mathrm{e}}$ eeuw en de eenheid van het wetenschappelijk denken', in W.W. Mijnhardt and B. Theunissen (eds.), De Twee Culturen. De eenheid van kennis en haar teloorgang (Amsterdam, 1988). In The Two Cultures there is, however, no reference to Sarton at all.

7 Sarton, A Guide to the History of Science, I 4.

8 Ibid.,I3.

9 Kragh, Introduction, I9.

Io A. Rupert Hall, 'Beginnings at Cambridge', Isis (I984), 22-25.

I I E.A. Burtt, The Metaphysical Foundations of Modern Science (New York, I 954 [I 924 ]), 25.

I2 As pointed out in Cohen, The Scientific Revolution. The idea of 'thinking cap' was further developed by Thomas Kuhn into the notion of paradigm.

I 3 See A. Koyré, Études Galiléennes (Paris, I939).

I4 E.J. Dijksterhuis, The Mechanization of the World Picture (I950).

I5 Cohen, The Scientific Revolution, 79.

I6 Steven Shapin, Never Pure: Historical Studies of Science as if It Was Produced by People with Bodies, Situated in Time, Space, Culture, and Society, and Struggling for Credibility and Authority (Baltimore, 2010), 3-14: 'Lowering the tone in the history of science'.

I7 A. Elzinga, 'Wetenschapsgeschiedenis van overzee. Congresverslag', Skript 8 (I987), 263270, esp. 267.

I 8 In Nicholas Jardine, 'Whigs and Stories: Herbert Butterfield and the Historiography of Science', History of Science 4I.2 (2003), I25-I 40, the first usages of the term are traced.

I9 As Floris Cohen pointed out to me lack of scientific background is perhaps the most profound reason why 'mainstream' historians en masse leave out science as an important determining factor of the history of mankind.

20 In the collection of essays in both N. Koertge (ed.), A House Built on Sand: Exposing Postmodernist Myths about Science (Oxford, I998) and Ullica Segerstråle (ed.), Beyond the Science Wars: The Missing Discourse about Science and Society (New York, 2000), an 
attempt is made to strike a balance after the storm had died down. The former is still quite belligerent, while the explorations to move beyond the 'wars' in the latter remain somewhat inconclusive.

2I James B. Conant was one of the main driving forces behind this process as mentioned in Robert S. Westman, 'Two Cultures or One? A Second Look at Kuhn's The Copernican Revolution', Isis 85 (I994), 79-I I 5. Kuhn also mentioned the profound impact of scientific findings on the course of the war as a motivation to increase attention for history of science. A useful survey is also J. W. Dauben, M.L. Gleason, and G.E. Smith,'Seven Decades of History of Science: I. Bernhard Cohen, I9I4-2003, Second Editor of Isis', Isis Ioo- Io I (2009), 4-35.

22 Thomas S. Kuhn, 'Professionalization Recollected in Tranquility', Isis 75.I (I984), 29-32.

23 That this fear is widespread can, for example, be seen in the recurrent topos of the mad and bad scientist in film and literature.

24 Thomas S. Kuhn, The Structure of Scientific Revolutions (Chicago, I962).

25 This message was radicalized in Feyerabend's well-known Against Method: Outline of an Anarchistic Theory of Knowledge (I975). Instead of Kuhn I could also have chosen other examples of new approaches to science using new analytical concepts to study the specifics of historical contexts, such as Robert K. Merton, who came with a sociology of institutions and Stephen Toulmin, who developed a study of scientific disciplines as ecological 'niches' via an analogy with the theory of evolution.

26 In fact the whole mirror metaphor was cast aside in favor of constructivist points of view. See especially Richard Rorty, Philosophy and the Mirror of Nature (Princeton, 1979).

27 Note that Kuhn himself changed his position, but in the opposite direction. On the problem of incommensurability of paradigms he proposed that with respect to a number of virtues, such as simplicity, accuracy and scope, interparadigmatic comparisons were possible thus offering an alternative standard of progress.

28 For naturalism in relation to the study of (past) science, see Philip Kitcher,'The Naturalists Return', Philosophical Review Ior.I (I992), 53-II4.

29 David Bloor, Knowledge and Social Imagery (London, 1976).

30 According to Steven Shapin, 'Discipline and Bounding: The History and Sociology of Science as Seen through the Externalism-Internalism Debate', History of Science 30 (I992), this message still awaited full recognition in historiography of science as late as I992.

3I One of the most important generalizations of symmetry can be found in Bruno Latour, We Have Never Been Modern (Boston, 199I). For an overview of generalizations, see D. Pels, 'The Politics of Symmetry', Social Studies of Science 26.2 (I996), 277-304.

32 The same observation can be found in J.M. Kuukkanen, 'The Missing Narrativist Turn in the Historiography of Science', History and Theory 5I.3 (2012), 340-363.

33 J. Golinski, Making Natural Knowledge: Constructivism and the History of Science (Chicago and London, 2005).

34 Geert van Paemel, 'Introduction: Networks and Institutions in the Circulation of Knowledge', Studium 4.4 (201 I), I93-I94.

35 See G.G. Iggers, Historiography in the 2oth Century: From Scientific Objectivity to the Postmodern Challenge, 2nd ed. (Middletown, 2005).

36 Note that the network model of Bruno Latour, based on generalized symmetry, offers a global perspective in which localities are connected to each other. Yet this is allowed only if these localities can be related through concrete interaction of actors. Therefore the global in Latour remains local no matter how big the network eventually becomes. 
37 It is therefore not surprising that attempts to declare oneself independent have not been very convincing. Examples: Paul Forman, 'Independence, Not Transcendence, for the Historian of Science', Isis 827 I (I99I), 7I-86, is a late cry to finally get rid of Whiggism. Jardine, 'Sammlung, Wissenschaft, Kulturgeschichte', calls for an end to theoretical anarchy by choosing one model of interpretation, namely the ideas of Norbert Elias on the civilization process. Historians of science should cooperate with other cultural historians in bringing the full understanding of this process about. Yet, Elias was a sociologist and the dominant model then would still be sociological. Hasok Chang, 'We Have Never Been Whiggish (About Phlogiston)', Centaurus 5I (2009), 239-264, calls for an independent judgmentalism for history of science but it remains unclear what this judgmentalism should be based on.

38 An example is given by the puzzling number of measurements of the ratio of the electron's mass and charge carried out by J.J. Thompson. If modern knowledge is used, these measurements can be understood much better. Argument taken from Stephen Weinberg, 'Sokal's Hoax', The New York Review of Books XLIII-I 3 (I996), I I-I 5.

39 Hasok Chang has argued that the history of science can have complementary functions to science because important lines of research may have become forgotten that can still be relevant for present-day research. The historian can reopen such forgotten lines of research. It is different in its formulation but this way of thinking is clearly in Sartonian spirit. Hasok Chang,'History and Philosophy of Science as a Continuation of Science by Other Means', Science and Education 8 (1999), 4I3-425.

40 Ken Alder, 'The History of Science, or, an Oxymoronic Theory of Relativistic Objectivity', in Lloyd Kramer and Sarah Maza (eds.), A Companion to Western Historical Thought (London, 2002), 297-3I8, warns that the history of science can no longer perform its critical functions. Nicholas Jardine has expressed the same worry: "[S]hould the history of science lose the critical functions Butterfield assigned to it, it would become pointless' (Nicholas Jardine, 'Whigs and Stories', I36).

4I Thomas S. Kuhn, The Structure of Scientific Revolutions (Chicago: University of Chicago Press, I962), 88.

42 See, for example, David Bloor, Wittgenstein: A Social Theory of Knowledge (New York: Macmillan, I983), or Bloor, Wittgenstein: Rules and Institutions (Florence, KY: Routledge, I997).

43 This holds especially for Bloor and Latour.

44 For the last, see Giora Hon, Jutta Schickore, and Friedrich Steinle (eds.), Going Amiss in Experimental Research (New York: Springer, 2009).

45 One reviewer suggested that the comparative approach could be the primary resource for the improvements sought in the paper. I am very sympathetic to this suggestion and working on a dissertation at the University of Leiden, in the 'Philosophical Foundations of the Historiography of Science' project, that will contain a discussion on comparativism. The trouble is that the approach has never been articulated very well and has turned into a fringe phenomenon. Almost all contributions to comparative historiography of science are brought together in Lewis Pyenson, 'Comparative History of Science', History of Science 40.I (2002), I-33. The most important theoretical explorations stem from the social sciences and from the I980s: Charles Tilly, Big Structures, Large Processes, Huge Comparisons (New York: Russell Sage Foundation, 1984), Charles Ragin, The Comparative Method: Moving Beyond Qualitative and Quantitative Strategies (Los Angeles: University of California Press, 1987). More recent short papers offering valuable suggestions are by Chris Lorenz, 'Comparative Historiography: Problems and Perspectives', History and 
Theory 38 (1999), 25-39, and Margaret C. Jacob, 'Science Studies after Social Construction: The Turn toward the Comparative and the Global', in Victoria Bonnell and Lynn Hunt (eds.), Beyond the Cultural Turn: New Directions in the Study of Society and Culture (Berkeley: University of California Press, 1999). All this is not much but the tide may be turning as a number of possibly groundbreaking books explicitly based on the comparative approach have recently appeared: G.E.R. Lloyd, Disciplines in the Making: Cross-Cultural Perspectives on Elites, Learning and Innovation (Oxford, 2009), H. Floris Cohen, How Modern Science Came into the World: Four Civilizations, One 17th-Century Breakthrough (Amsterdam, 2010), Rens Bod, A New History of the Humanities (Oxford, 2013). 